\title{
FEA Based Simulation and Experimental Analysis of Forces in Dry Milling of Inconel 718
}

\author{
N. Bauskar ${ }^{1}$, R. Mali ${ }^{2}$, T. Gupta ${ }^{3 *}$ \\ ${ }^{1}$ PG Student, ${ }^{2}$ Research Scholar, ${ }^{3}$ Assistant Professor \\ Visvesvaraya National Institute of Technology, Nagpur, India \\ \{tvkgupta@mec.vnit.ac.in\}
}

\begin{abstract}
Machining process simulation is an important aspect in the manufacturing context that generates a scenario to enhance the process performance in terms of time and cost. With unique high temperature and stress properties and applications of Inconel 718 material in various sectors of engineering, the machinability assessment has become an important issue which needs a detailed investigation. The present work has been attempted to study and compare experimental results with simulation results based on finite element approach in dry milling of Inconel 718 with coated carbide inserts. During machining of Inconel 718, cutting tool environment reaches very high localized temperatures and high stresses due to repeated impact loads during interrupted cutting. The milling tests were conducted under various cutting conditions to investigate their effect on the response parameters. A simulation model based on finite element approach is proposed using DEFORM 3D to investigate cutting forces in end milling operation. The simulation results are validated with the experimental trials. An average error of $7 \%$ is obtained in the response function.
\end{abstract}

Keywords: Inconel 718, Numerical Simulation, Deform 3D, Cutting forces

\section{Introduction}

In the present day engineering, difficult to cut materials are being used extensively for high temperature and pressure applications that demands high accuracy. Inconel 718, a Nickel based alloy is mostly preferred because of its high thermal and fatigue strength [1]. Some of the disadvantages in machining Inconel 718 include high heat generation causing extensive tool wear and higher tool expenses. However, recent advances in coatings (CVD and PVD) enable to machine difficult to cut materials with improved performance. High speed milling of Inconel 718 with cryogenic treated tungsten carbide tools has shown better work hardening characteristics [2]. Simulation modeling can be used to predict the machining behaviour that effectively reduces the time and cost of experimentation. These techniques are essentially used to ensure and improve the process performance and analyse the machinability behaviour with physics based modeling. The efforts on using FEA based simulation techniques to predict the effect of process parameters and consequently optimise them in machining of different materials were well recognized. Further, efforts were extended in understanding and simulating the machining characteristics like interface temperature, cutting forces, stresses and chip formation. However, in elastic-viscoplastic domain, most FEA based approaches are coupled with numerical convergence due to insufficient material models available. All physics based models available in the literature are based on basic material properties, strain, and temperature in machining.

Aurich and Bill [3] proposed FEM based simulation approach to understand the segmented chip formation in metal cutting. Usui et al. [4] analytically developed a model to investigate crater and flank wear of tungsten carbide tool. The wear characteristic equations are also developed and verified experimentally. Zhao et al. [5] studied the effect of internal cooling on the flank wear in orthogonal cutting. The report also presents a flank wear study for the normal stress condition considering thermal softening of the material. Arsecularatne and Zhang [6] discussed the wear mechanisms of various cutting tools considering tool interface temperature and tool life.The present study attempts a FEA based simulation in dry milling of Inconel 718 to understand the machining behaviour in terms of forces and it also emphasizes experimental validation of the simulation results.

B. Iyer, S. Nalbalwar and R. Pawade (Eds.)

ICCASP/ICMMD-2016. Advances in Intelligent Systems Research.

Vol. 137, Pp. 206-211.

(c) 2017. The authors - Published by Atlantis Press

This is an open access article under the CC BY-NC license (http://creativecommons.org/licens)es/by-nc/4.0/).

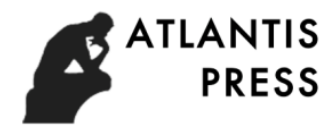


The present work uses Johnson-Cook constitutive material model, friction and tool wear model to validate the simulation results for cutting force and comparing with experimental data.

\section{Finite Element Model}

\subsection{Introduction}

FEM provides a systematic approach to model approximation functions for motion, force, deformation, and temperature. A complex metal cutting phenomenon can be simulated with FEM approach under some assumptions. These assumptions are essentially made to define and simplify the problem by applying boundary conditions. Present study have used DEFORM ${ }^{\mathrm{TM}}$ - 3D, a FEA based simulation software and analysis platform to understand machining process using Lagrangian formulation. The Newton-Raphson time integration method has been used for each time step. The Newmark family of temporal integrators is used to solve the algorithmic approximations for the solution vector of displacement, velocity and acceleration. Explicit time integration scheme is applied to solve the equations.

\subsection{Material model}

The material constitutive model explains the effect of strain, strain rate, and temperature on flow stress. These material models are developed to understand the material behaviour and are the experimental models only. Recently, Johnson-Cook material model (Eq. 1) has been used extensively by researchers for metal cutting analysis.

$\bar{\sigma}=\left[A+B \bar{\varepsilon}^{n}\right] \times\left[1+C \ln \left(\frac{\dot{\bar{\varepsilon}}}{\dot{\overline{\varepsilon_{0}}}}\right)\right] \times\left[1-\left(\frac{\mathrm{T}-\mathrm{T}_{\mathrm{r}}}{\mathrm{T}_{\mathrm{m}}-\mathrm{T}_{\mathrm{r}}}\right)^{\mathrm{m}}\right]$

Where, $\bar{\sigma}$ is Flow stress, $\varepsilon$ is equivalent plastic strain, A is Yield stress constant, $\dot{\bar{\varepsilon}}$ is Strain rate, B is Strain hardening coefficient, $\dot{\overline{\varepsilon_{0}}}$ is reference strain rate, $\mathrm{n}$ is Strain hardening exponent, $\mathrm{T}$ is Temperature, $\mathrm{C}$ is Strain rate dependence coefficient, $\mathrm{Tr}$ is Room temperature, $\mathrm{M}$ is Temperature dependence coefficient and $\mathrm{Tm}$ is Melting temperature.

The above Eq. 1 found to represent the correlation of strain, strain rate, and temperature with flow stress, if not perfectly, for many materials. The constants, [7] mentioned in Johnson-Cook material model are usually computed from Split Hopkinson Pressure Bar (SHPB) test or ballistic impact tests from regression analysis that are presented in Table 1. Non-linear material properties, high strain and strain hardening during dry milling of Inconel 718 made it suitable to use the Johnson-Cook material model for simulation $[7,8]$.

Table 1 Johnson-Cook model constants for Inconel 718

\begin{tabular}{|c|c|c|c|c|c|c|c|}
\hline $\mathrm{A}(\mathrm{MPa})$ & $\mathrm{B}(\mathrm{MPa})$ & $\mathrm{n}$ & $\mathrm{C}$ & $\mathrm{M}$ & $\dot{\overline{\varepsilon_{0}}}(1 / \mathrm{s})$ & $\operatorname{Tr}\left({ }^{\circ} \mathrm{C}\right)$ & $\operatorname{Tm}\left({ }^{\circ} \mathrm{C}\right)$ \\
\hline 450 & 1700 & 0.65 & 0.017 & 1.3 & 0.001 & 20 & 1300 \\
\hline
\end{tabular}

In the metal cutting process, the tool-work piece contact area friction plays an important role. It defines the ease and quality of machining as it determines interface temperature, tool life and chip geometry. The friction force is generally determined using Coulomb's law that is mentioned in Eq. 2. In the present study, the shear friction value $\mu$ is taken as $0.6[8]$.

$$
\mathrm{fS}=\mu . \sigma \mathrm{t}
$$

Where, $\mathrm{fS}=$ Fictional stress, $\mu=$ Shear friction factor, $\sigma \mathrm{t}=$ Interface pressure.

$$
\frac{d w}{d t}=A \sigma_{t} V \exp \left(\frac{-B}{\theta}\right)
$$

Where, $\mathrm{w}=$ Flank wear, $\mathrm{V}=$ Sliding velocity, $\theta=$ Interface temperature

Usui tool wear model (Eq. 3) has been used to study and evaluate the wear during the machining process. The parameters like temperature and pressure at tool workpiece interface, and sliding velocity are considered from every simulation run [4]. This wear model emphasises that the flank wear, which is a function of tool work piece 
relative velocity, interface pressure, and absolute temperature. In the present work, the tool wear constants considered as, $\mathrm{A}=0.0000000078$ and $\mathrm{B}=5302$ [9-11].

\subsection{Cutting tool (insert) model}

Tungsten carbide inserts with PVD coatings of TiAlN and $\mathrm{Al}_{2} \mathrm{O}_{3}$ (Walter make, tool designation: SPMT09T308F55 WSM35) are used for experimentation. The detailed tool geometry $\left(1=9.52, \mathrm{~s}=3.97, \mathrm{r}=0.8, \alpha=11^{\circ}\right)$ is shown in fig. 1 (a), same is modelled in SolidWorks ${ }^{\text {TM }} 2014$ modelling software (shown in Fig. 1b).

(a)

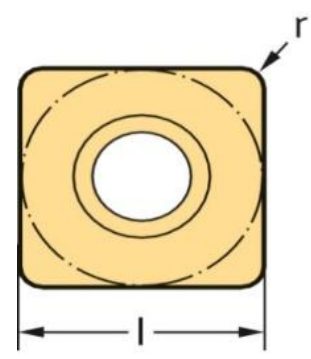

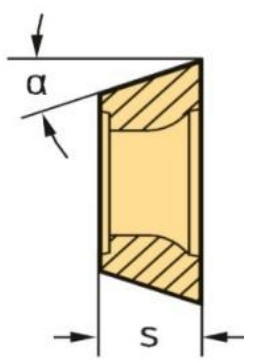

(b)

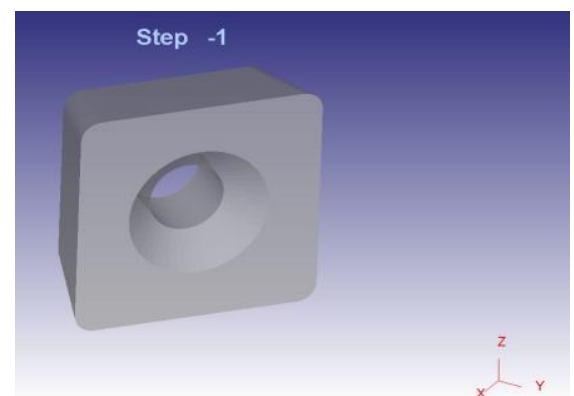

Fig.1. (a) Geometric details and (b) 3D model of tool

\subsection{Workpiece model with adaptive remeshing}

This study uses third-order triangular elements with six nodes in DEFORM ${ }^{\mathrm{TM}}$ 3D to formulate initial material model and discretization. Lagrangian mesh which is used to define the mesh, is mostly featured with severe mesh distortion. This leads to need for continuous re-meshing to minimize or avoid mesh distortion problems. However, to enhance the positive effects of adaptive re-meshing, simple mesh smoothing algorithms are applied. In general, these algorithms are suitably used to ensure the boundary layers that are developed in the contact region and within their localized shear bands. Similarly, Laplacian smoothing and mesh coarsening algorithms are used to improve and ensure effective meshing, which will be help to avoid residual distortions and reduced problem size to enhance efficient computation.

\subsection{Numerical simulation}

Milling option is selected in DEFORM ${ }^{\mathrm{TM}} 3 \mathrm{D}$ and the parameters are set at different levels of speed, feed and depth of cut as shown in Table 2, keeping a constant tool diameter of $25 \mathrm{~mm}$.

Table 2 Domain of experimentation

\begin{tabular}{|c|c|c|c|}
\hline Factors & Level1 & Level2 & Level3 \\
\hline Speed $(\mathrm{rpm})$ & 350 & 475 & 600 \\
\hline Feed $(\mathrm{mm} / \mathrm{z})$ & 0.05 & 0.375 & 0.700 \\
\hline D.O.C. $(\mathrm{mm})$ & 0.5 & 1.25 & 2.0 \\
\hline $\begin{array}{l}\text { Environment temperature }\left({ }^{\circ} \mathrm{C}\right)=20^{\circ}, \text { Shear friction coefficient }=0.6, \text { Heat transfer } \\
\text { coefficient }\left(\mathrm{N} / \mathrm{sec} / \mathrm{mm} /{ }^{\circ} \mathrm{C}\right)=45, \text { and Convection coefficient }=0.2\end{array}$ \\
\hline
\end{tabular}

Width of cut is the algebraic difference of dimensions of square on the work piece and square block. MRR was measured in $\mathrm{mm} 3 / \mathrm{min}$ and overcut in $\mathrm{mm}$. Statistical analysis was carried out using Minitab 16 software. Table 2 shows Taguchi's L27 orthogonal design along with the results obtained from the experiments and corresponding $\mathrm{S} / \mathrm{N}$ ratios.

\section{Experimentation}

\subsection{Experimental set up}


All the experimental trails are performed on a Vertical Machining Centre (VMC) (Smart Mill 500, Make: Askar Microns Ltd. India) to assess the effect of machining parameters on cutting forces. An Inconel 718 plate of dimensions $150 \mathrm{~mm} \times 150 \mathrm{~mm} \times 10 \mathrm{~mm}$ (shown in Fig. 2) has been used for experimentation. All the experiments are conducted for a cut length of $35 \mathrm{~mm}$ only.
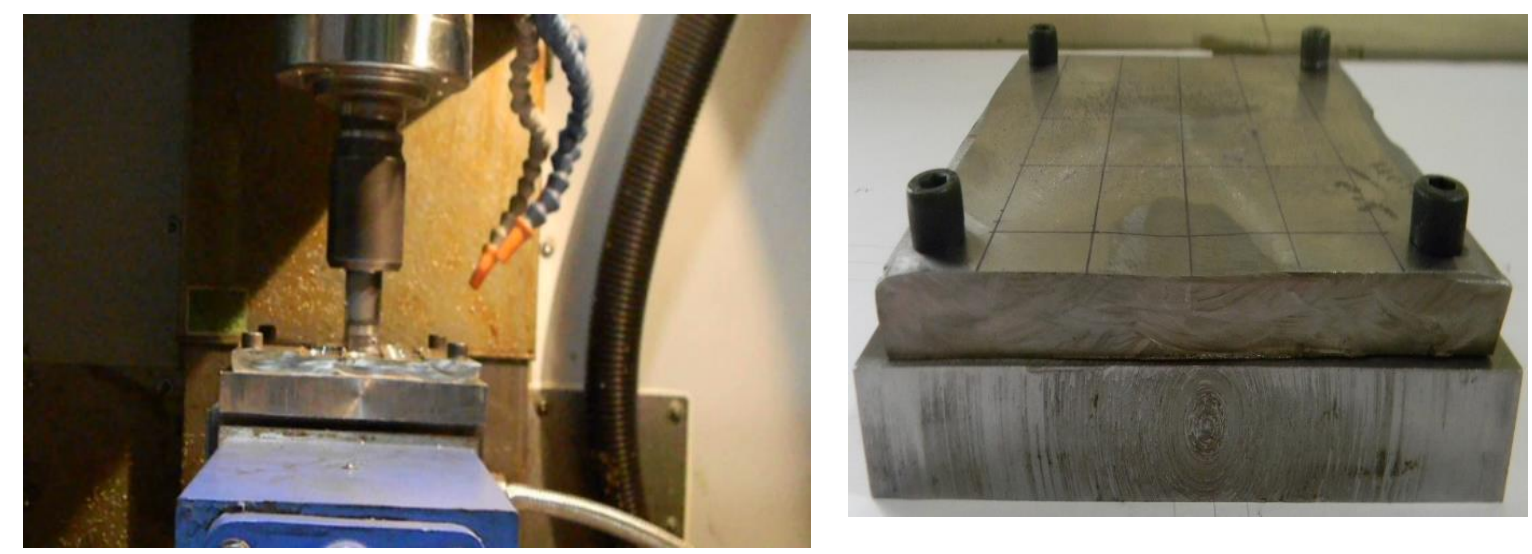

Fig. 2. Experimental set up showing fixture and workpiecemounting

\subsection{Measurement of cutting forces}

A KISTLER dynamometer (Model No. 9257B) having $10 \mathrm{KN}$ load capacity is used in present work. National Instruments (NI) Data acquisition card (NI-Card: NI cDAQ-9178) is used for data acquisition. The sampling frequency is set at $12000 \mathrm{~Hz}$ and LabView software is used to record the data.The relevant cutting force data is extracted using raw force data and processing has been done in MatLab signal processing tool.

\section{Results and Discussion}

The complete machining simulation is carried with DEFORMTM 3D Machining to extract the values of cutting forces. Simultaneously, the experimental data for the cutting forces has been generated under same machining conditions. Table 3 gives the data generated from experiments and through simulation. The two components of cutting forces that has been recorded are (a) Feed force Fx, (b) Normal or Thrust force Fy. Both the experimental and simulation forces are plotted with time in seconds. Fig. 3 shows the experimental force data and the simulation results obtained from DEFORM ${ }^{\mathrm{TM}} 3 \mathrm{D}$.
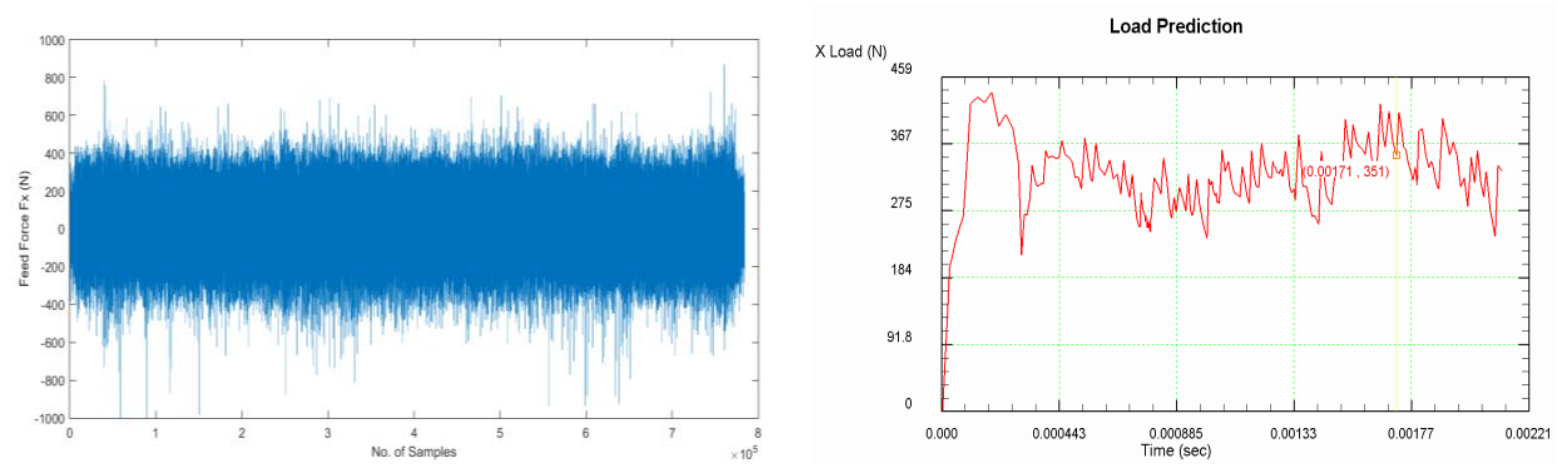

Fig. 3. Feed Force (N) vs No. of Samples (experimental result) and time (simulation result)

Analysis on the experimental force and simulation for every trial has been carried and the data is presented in Table 3. While, Fig. 4 shows the graphical comparison of simulation and experimental forces. 
Table 3 Experimental and simulation results for cutting forces (with \% error)

\begin{tabular}{|c|c|c|c|c|c|c|c|c|c|}
\hline \multirow{2}{*}{$\begin{array}{l}\text { Std. } \\
\text { Order }\end{array}$} & \multicolumn{3}{|c|}{ Process Parameters } & \multicolumn{2}{|c|}{ Experimental Results } & \multicolumn{2}{|c|}{ Simulation Results } & \multicolumn{2}{|c|}{ \% Relative Error } \\
\hline & $\begin{array}{l}\text { Speed } \\
(\mathrm{rpm})\end{array}$ & $\begin{array}{c}\text { Feed } \\
(\mathrm{mm} / \mathrm{z})\end{array}$ & $\begin{array}{l}\text { D.O.C } \\
(\mathrm{mm})\end{array}$ & $\mathrm{F}_{\mathrm{x}}(\mathrm{N})$ & $\mathrm{F}_{\mathrm{y}}(\mathrm{N})$ & $\mathrm{F}_{\mathrm{x}}(\mathrm{N})$ & $\mathrm{F}_{\mathrm{y}}(\mathrm{N})$ & $\mathrm{F}_{\mathrm{x}}(\mathrm{N})$ & $\mathrm{F}_{\mathrm{y}}(\mathrm{N})$ \\
\hline 4 & 600 & 0.7 & 1.25 & 331.28 & 412.67 & 310.28 & 386.62 & 6.58 & 6.74 \\
\hline 1 & 350 & 0.05 & 1.25 & 471.52 & 577.21 & 429.35 & 526.89 & 9.82 & 9.55 \\
\hline 10 & 475 & 0.7 & 0.5 & 513.37 & 687.32 & 462.45 & 617.70 & 11.01 & 11.27 \\
\hline 2 & 600 & 0.05 & 1.25 & 142.79 & 237.15 & 139.24 & 230.80 & 2.55 & 2.75 \\
\hline 12 & 475 & 0.7 & 2 & 639.06 & 887.31 & 601.13 & 832.15 & 6.31 & 6.63 \\
\hline 7 & 350 & 0.375 & 2 & 460.32 & 626.53 & 439.78 & 602.55 & 4.67 & 3.98 \\
\hline 15 & 475 & 0.375 & 2 & 257.18 & 419.13 & 251.95 & 410.11 & 2.08 & 2.20 \\
\hline 9 & 475 & 0.05 & 0.5 & 318.93 & 296.07 & 302.65 & 279.95 & 5.38 & 5.76 \\
\hline 3 & 350 & 0.7 & 1.25 & 795.61 & 1145.5 & 710.75 & 1025.84 & 11.94 & 11.67 \\
\hline 8 & 600 & 0.375 & 2 & 162.25 & 342.83 & 149.3 & 314.8 & 8.68 & 8.90 \\
\hline 6 & 600 & 0.375 & 0.5 & 243.95 & 369.66 & 220.97 & 335.7 & 10.40 & 10.12 \\
\hline 11 & 475 & 0.05 & 2 & 186.60 & 461.55 & 173.54 & 430.75 & 7.53 & 7.15 \\
\hline 14 & 475 & 0.375 & 0.5 & 344.49 & 512.44 & 313.84 & 466.71 & 9.77 & 9.80 \\
\hline 5 & 350 & 0.375 & 0.5 & 656.17 & 767.26 & 630.26 & 734.01 & 4.11 & 4.53 \\
\hline 13 & 475 & 0.375 & 1.25 & 412.13 & 532.40 & 377.24 & 485.01 & 9.25 & 9.77 \\
\hline \multicolumn{8}{|c|}{ Average Relative Error } & 7.33 & 7.388 \\
\hline 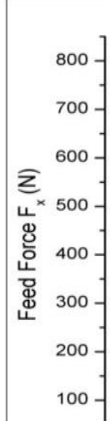 & 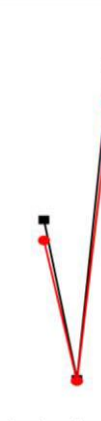 & 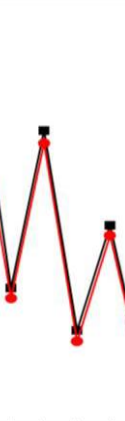 & & $\begin{array}{l}\text { - - Experiment } \\
\text { - Simulation }\end{array}$ & 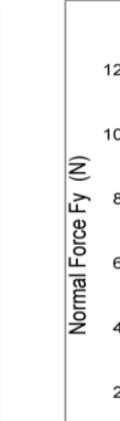 & & & & $\begin{array}{l}\text { Experiment } \\
\text { Simulation }\end{array}$ \\
\hline & 2 & $\begin{array}{cc}4 & 1 \\
4 & \text { Exper } \\
& \end{array}$ & $\begin{array}{c}10 \\
\text { tal Run }\end{array}$ & $14 \quad 16 \quad(a)$ & & 0 & $\begin{array}{ccc} & 1 & 1 \\
6 & 8 \\
\text { Experimen }\end{array}$ & $\begin{array}{ll}10 & 12 \\
10 & 12 \\
\text { Run }\end{array}$ & ${ }_{16}^{16}(\mathrm{~b})$ \\
\hline
\end{tabular}

Fig. 4. Comparison between experimental and simulation results (a) Feedand (b) Normalforce

Influence of different machining parameters on cutting forces has been investigated. It is observed that cutting force decreases as cutting speed increases, whereas it increases almost linearly with the increase of bothfeed and axial depth of cut.

\section{Conclusions}

Generally, the machinability of Inconel 718 is poor; however the results showed that, it could be machined satisfactorily in the speed range of $350-450 \mathrm{rpm}$, feed at $0.05-0.25 \mathrm{~mm} /$ tooth and axial depth of cut up to 1.5 $\mathrm{mm}$. The experimental simulation results shows that cutting force in dry milling decreases as the cutting speed increases while it increases with increase in feed or depth of cut or both. The influence of machining parameters 
on performance characteristics in dry milling is investigated. The FEA based numerical model has been developed to estimate the response using DEFORM 3D. These models are validated experimentally with an average relative error of $7.3 \%$. The model thus developed is well within a reliable accuracy limit and can be used successfully to predict the performance in terms of cutting force and other characteristics that could enable the shop floor engineers to reduce the experimental efforts.

\section{References}

[1]. E. Ezugwu, Z. Wang, and A. Machado, "The machinability of nickel-based alloys: a review", Journal of Materials Processing Technology, 86 (1999) 1-16.

[2]. D. G. Thakur, B. Ramamoorthy, and L. Vijayaraghavan, "Effect of cutting parameters on the degree of work hardening and tool life during high speed machining of Inconel 718", International Journal of Advanced Manufacturing Technology, 59 (2012) 483-489.

[3]. J. C. Aurich, and H. Bil, “3D Finite Element Modelling of Segmented Chip Formation”, CIRP AnnalsManufacturing Technology, 55 (2006) 47-50.

[4]. Usui, T. Shirakashi, and T. Kitagawa, “Analytical prediction of cutting tool wear", Wear, 100 (1984) 129-151.

[5]. H. Zhao, G. C. Barber, and Q. Zou, "A study of flank wear in orthogonal cutting with internal cooling", Wear, 253 (2002) 957-962.

[6]. J. A. Arsecularatne, L. C. Zhang, and C. Montross, "Wear and tool life of tungsten carbide PCBN and PCD cutting tools", International Journal of Machine Tools and Manufacture, 46 (2006) 482-491.

[7]. E. Uhlmann, M. G. Schulenburg, and R. Zettier, "Finite element modeling and cutting simulation of Inconel 718”, Annals of the CIRP, 56 (2007) 61-64.

[8]. C. Ezilarasan, V. S. Senthilkumar, and A. Velayudham, "Theoretical predictions and experimental validations on machining the Nimonic C-263 super alloy", Simulation Modelling Practice and Theory, 40 (2014) 192-207.

[9]. Y. C. Yen, J. Sohner, B. Lilly, and T. Altan, "Estimation of tool wear in orthogonal cutting using the finite element analysis" Journal of Materials Processing Technology, 146 (2004) 82-91.

[10].T. Tamizharasan, and N. S. Kumar "Optimization of cutting insert geometry using DEFORM-3D numerical simulation and experimental validation”, International Journal of Simulation Modelling, 11 (2012) 65-76.

[11].B. Li, "A review of tool wear estimation using theoretical analysis and numerical simulation technologies”, International Journal of Refractory Metals and Hard Materials, 35 (2012) 143-151. 